\title{
Idiopathic clubfoot: past, present and future
}

Congenital clubfoot is a complex — and relatively common—foot deformity affecting about one to two children in 1,000 births, and twice as many boys as girls; both feet are affected in almost $50 \%$ of cases.

The clinical examination of patients with clubfoot must be very careful with the background of a possible underlying cause in up to $10 \%$ of cases. Antenatal diagnosis is currently possible in most cases and it is usually done on the second ultrasound, between the $20^{\text {th }}$ and the $22^{\text {nd }}$ week of gestation. Antenatal ultrasound also looks for other abnormalities sometimes associated with clubfoot; in particular, bilateral forms can be associated with chromosomal abnormalities, syndromes or agenesis of the corpus callosum.

In this context, clubfoot classifications play an essential role in the management of patients with clubfoot deformity. In particular, classifications are extremely useful to distinguish the forms according to their clinical severity, to select the best treatment plan as well as to evaluate and compare homogeneous group of patients.

Clubfoot correction can be obtained by different techniques, such as the French functional physical therapy (FFPT) method, based on manipulations and splints $(1,2)$, or the Ponseti technique, based on serial casting $(3,4)$. Both methods share the same goal, and aim to obtain a supple, painless and plantigrade foot, to decrease the extent and the frequency of surgery, and to reduce the risk of relapse.

Regardless of the fact that since their introduction the two techniques have evolved, they are based on two fundamental principles described during the $18^{\text {th }}$ and $19^{\text {th }}$ century by Antonio Scarpa (Italy), Luis Hubert Frabeuf (France) and JacquesMathieu Delpech (France). Delpech, in his work "De l'orthomorphie" (1828) describes a severe clubfoot treated by an Achilles tendon lengthening followed by the use of a specific apparatus. Delpech already pointed out the most difficult deformity to correct is the equinus, and that as long as there is equinus there is still varus, and as long as there is varus there is still supination and adduction of the forefoot. Scarpa and Farabeuf emphasized that clubfoot correction must start in the horizontal plane as horizontal plane correction minimizes equinus. At the same time, forefoot correction and derotation of the calcaneopedal complex around the talus are performed $(1,4)$. In addition, Ponseti understood that extensive surgery was responsible for poor results and that fibrosis was the enemy to fight against.

Although benefits, virtues and advantages of conservative treatment are now recognized, no treatment is able to completely eradicate surgery. The recently introduced 'bybrid method' highlights the conservative treatment of tomorrow is probably half-way between the method introduced by Ponseti and the FFPT method, and from this point one can expect to improve results. In particular, regular manipulations can benefit to patients treated by the Ponseti protocol, as the first results of the 'bybrid method' seem to suggest (5). A careful manipulation by a skilled physical therapy for 30 minutes before cast application can improve results, and speed up the reduction of the foo by increasing its flexibility. In addition, regular physical therapy can reduce the risk of relapse.

Indisputably conservative treatments are effective though they also started an excessive enthusiasm, with short-term publications ringing as declarations of victory. Brutally, surgery has been forgotten, and even despised. It is obvious that each conservative method and technique has its own advantages and disadvantages, and whatever treatment, the more severe deformity carries the higher risk of surgery. Following the coming back of conservative treatment, a new surgery-limited, thrifty, kind-has born: the 'surgery à la carte' which joins the French philosophy (6).

This special series, thanks to the enthusiastic participation of many experts in the field, tries to give a comprehensive overview of the clubfoot pathology, and an objective analysis of the outcome of treatments. The members of leading medicalsurgical teams dedicated to the care of children with clubfoot agreed to share their experience and their thoughts on the subject, making this series of articles a unique document summarizing the 'state of the art' of clubfoot treatment and its outcome in different part of the world.

Rather than comparing them, the time has come to reconcile the differences between the different treatment protocols, in order to merge together the advantages of each technique, and to include them in the same strategy in order to improve the care and the quality of life of children with clubfoot. 


\section{Acknowledgments}

Funding: None.

\section{Footnote}

Provenance and Peer Review: This article was commissioned by the editorial office, Annals of Translational Medicine for the series "Clubfoot". The article did not undergo external peer review.

Conflicts of Interest: Both authors have completed the ICMJE uniform disclosure form (available at https://dx.doi.org/10.21037/ atm-21-2392). The series "Clubfoot" was commissioned by the editorial office without any funding or sponsorship. FC and $\mathrm{AD}$ served as the unpaid Guest Editors of the series. FC serves as an unpaid editorial board member of Annals of Translational Medicine from Nov 2020 to Oct 2022. The authors have no other conflicts of interest to declare.

Ethical Statement: The authors are accountable for all aspects of the work in ensuring that questions related to the accuracy or integrity of any part of the work are appropriately investigated and resolved.

Open Access Statement: This is an Open Access article distributed in accordance with the Creative Commons AttributionNonCommercial-NoDerivs 4.0 International License (CC BY-NC-ND 4.0), which permits the non-commercial replication and distribution of the article with the strict proviso that no changes or edits are made and the original work is properly cited (including links to both the formal publication through the relevant DOI and the license). See: https://creativecommons.org/licenses/by-nc$\mathrm{nd} / 4.0 /$.

\section{References}

1. Dimeglio A, Canavese F. The French functional physical therapy method for the treatment of congenital clubfoot. J Pediatr Orthop B 2012;21:28-39.

2. Charles YP, Canavese F, Dimeglio A. Frühfunktionnelle Behandlung beim angeborenen Klumpfuß. Der Orthopäde 2006;35:665-74.

3. Ponseti IV. Clubfoot : fundamentals of treatment. Oxford University Press, 1996.

4. Cooper DM, Dietz FR. Treatment of idiopathic clubfoot. A thirty years experience. J Bone Joint Surg Am 1995;77:1477-89.

5. Canavese F, Mansour M, Moreau-Pernet G, et al. The hybrid method for the treatment of congenital talipes equinovarus: preliminary results on 92 consecutive feet. J Pediatr Orthop B 2017;26:197-203.

6. Bensahel H, Csukonyi Z, Desgrippes Y, et al. Surgery in residual clubfoot: one-stage medioposterior release "a la carte". J Pediatr Orthop 1987;7:145-8. 


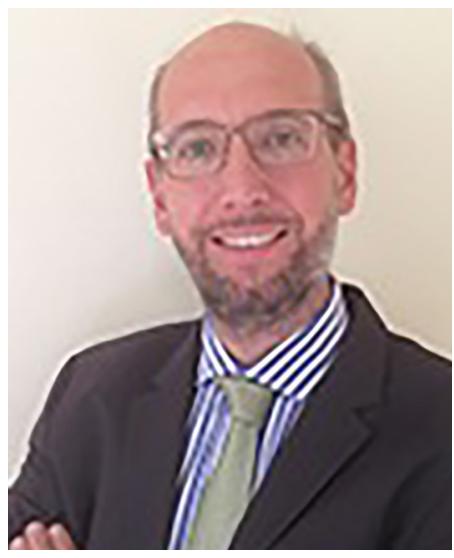

Federico Canavese

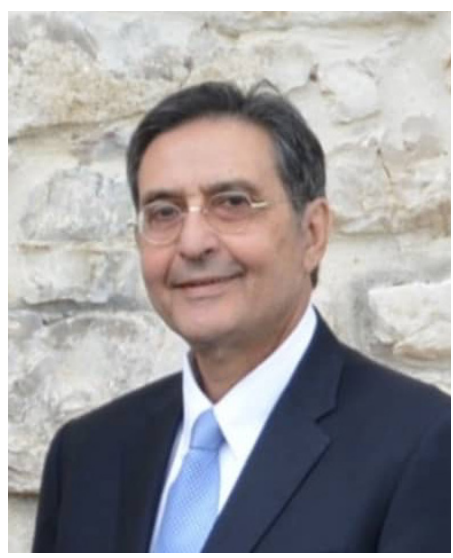

Alain Dimeglio

Federico Canavese ${ }^{1,2 \wedge}$

(Email: canavese_federico@yahoo.fr)

Alain Dimeglio ${ }^{3 \wedge}$

(Email: alaindimeglio@wanadoo.fr)

${ }^{1}$ Lille University Center, Feanne de Flandre Hospital, Department of Pediatric Orthopedic Surgery,

Rue Eugène Avinée, 59000 Lille France;

${ }^{2}$ Nord-de-France University, Faculty of Medicine Henri Warembourg, 2 rue Eugène Avinée, 59000 Lille, France;

${ }^{3}$ University of Montpellier, Faculty of Medicine, 2 Rue de l'École de Médecine, 34090 Montpellier, France.

Submitted May 07, 2021. Accepted for publication May 27, 2021. doi: $10.21037 / \mathrm{atm}-21-2392$

View this article at: https://dx.doi.org/10.21037/atm-21-2392

Cite this article as: Canavese F, Dimeglio A. Idiopathic clubfoot: past, present and future. Ann Transl Med 2021;9(13):1094. doi: 10.21037/atm-21-2392

\footnotetext{
^ ORCID: Federico Canavese, 0000-0002-6114-5372; Alain Dimeglio, 0000-0003-1371-1189.
} 